\title{
F-6 - Active Learning Using Protein Data Bank (PDB) Biochemical Data by Undergraduate Students of Nutrition Course at UFSC
}

\author{
Tânia Mara Fischer Günther ${ }^{1}$, Valdelúcia M.A.S. Grinevicius ${ }^{1}$, Rozangela Curi Pedrosa ${ }^{1}$ \\ ${ }^{1}$ Universidade Federal De Santa Catarina, Departamento De Bioquímica (SC, Brazil)
}

Support: Department-CCB-UFSC, UFSC Nutrition Course - Class 2017-2.

\begin{abstract}
INTRODUCTION: Many biochemistry internet sites lacking scientific accuracy dismiss their use. However PDB provides macromolecules structures that are experimentally very accurately determined. Besides, PDB provides biochemistry of nutritional chronic/metabolic diseases very useful to students and professionals. In addition, the $P D B$ provides biochemical knowledge of chronic and nutritional metabolic diseases very useful for students and professionals. However, PDB database idiom, sophisticate search tools and technical terms can be obstacles to active learning. OBJECTIVES: Incentive students to develop and improve their knowledge/learning network and skills needed to practice as professionals based in active learning of protein structures using PDB as a tool and scientific source of biochemical data obtained using computer structural models. MATERIALS AND METHODS. Firstly, traditional lectures showed basics concepts of the proteins biochemistry, accordingly to curricular content. Then, PDB protein categories showed (http://www.rcsb.org/pdb/home/home.do) using myoglobin as model (https:// pdb101.rcsb.org/motm/1). Finally, each pair of students select a protein to be described using Powerpoint ${ }^{\mathrm{TM}}$ format. Questions about pedagogic strategy and PDB aspects and all presentations were available at Moodle-UFSC (interactive virtual environment). DISCUSSION AND RESULTS: Students answers confirmed PDB structures as scientifically based (86\%). PDB was considered a good pedagogical strategy (44\%) rooted in scientific theory and experiment-based (48\%) with attractive computational molecular models $(57 \%)$. Students highlighted PDB give free/easy/fast access (53\%) and considered it as good to spread knowledge for all countries (61\%). PDB beneficiates Professors/Health professionals including Nutritionists (57\%) and Academy (74\%). CONCLUSION: Active learning process increase opportunities to access scientific curated PDB information capable to improve Biochemistry skills of future nutritionists. Acknowledgments: Biochemistry Department-CCB-UFSC, UFSC Nutrition Course - Class 2017-2.
\end{abstract}

Keywords: active learning; Biochemistry education; PDB database. 